\title{
Morphometric Methods for Examining the Liver in the Diagnosis of Acute and Chronic Alcohol Intoxication
}

\section{Porodenko VA* and Travenko EN}

Department of Forensic Medicine, Kuban State Medical University, Russia

*Corresponding author: Professor VA PORODENKO MD, DSc, Doctor of medical sciences, Department of Forensic Medicine, Kuban State Medical University, Krasnodar, Russia, Email: porodenko52@mail.ru

\section{Research Article}

Volume 6 Issue 1

Received Date: December 24, 2020

Published Date: January 22, 2021

DOI: $10.23880 /$ ijfsc- 16000221

\section{Abstract}

The article presents the results of a morphometric study of the liver of persons who died from acute ethanol intoxication and chronic alcohol intoxication in persons with alcohol-induced liver pathology. The aim of the work was to carry out morphometry of the main vascular and parenchymal structural components of the liver, reflecting its morphological and functional state.

Data were obtained on a decrease in the area of the vascular bed, cyto- and karyometric parameters, which reflect an increase in dystrophic processes in hepatocytes and inflammatory-proliferative processes in the connective tissue and indicate the tension of capillary-connective tissue structures, impaired blood circulation, bile and lymph outflow in the liver in chronic alcohol intoxication, especially with hepatitis and cirrhosis. The obtained morphometric data can be used as a comparison in studying the pathomorphological features of the liver in other pathological conditions.

Keywords: Acute and Chronic Alcohol Intoxication Morphometry of Liver Structures; Liver; Morphometry; Alcohol-Induced Liver Pathology

Abbreviations: AH: Alcoholic Hepatitis; AHP: Adaptive Hepatopathy; AS: Alcoholic Steatosis; AC: Alcoholic Cirrhosis; CAI: Chronic Alcohol Intoxication; NCR: Nuclear-Cytoplasmic Ratio.

\section{Introduction}

Currently, for forensic medicine, the problem of postmortem diagnosis of acute and chronic alcohol intoxication using modern research methods remains relevant, which allows not only to increase the accuracy of the description of the studied phenomena, but also to objectify the morphological verification of pathological processes [1-4].

Remaining basic, the qualitative assessment of pathomorphological changes in acute and chronic alcohol intoxication, and especially the liver as the main detoxifying organ, should be supplemented by quantitative studies micromorphometry, which allows obtaining more complete information about the processes occurring in hepatocytes under the influence of alcohol and can be used in the diagnosis and prediction of the outcome of emerging pathological processes [5].

At the present stage, morphometric models of various diseases and conditions have been studied, at the same time, there are practically no morphometric data on intraorgan blood and biliary tracts, hepatocytes and their nuclei in normal conditions and in ethanol poisoning [6-9].

Some of the studies studied are devoted to cyto- and karyometric parameters of the liver of experimental animals 


\section{International Journal of Forensic Sciences}

when modeling experimental alcoholic cirrhosis of the liver or in other conditions in combination with chronic ethanol intoxication [10-12]. At the same time, the authors assessed various morphometric characters, which, in our opinion, are not comparable, and sometimes contradictory.

Benyavsky MV [13] provides data on an increase in the diameters of nuclei in human liver cells with viral and alcoholic damage. A shift of the nucleus towards enlargement - $12 \mu \mathrm{m}$ and more, as well as an increase in the number of 2-nuclear hepatocytes, are characteristic of viral hepatitis, but not for alcoholic ones [14] Lebedeva EI [2016] in experimental studies, data were obtained on an increase in the average area of hepatocytes, especially at the stage of cirrhosis (by 1.5-1.75 times) in male and female rats, a decrease in the average number of binuclear hepatocytes and nuclear-cytoplasmic ratio (NCR) in 1,2 times compared to control. In humans, there were no changes in the average area of hepatocytes with steatosis and cirrhosis relative to the control group. At the same time, at the stage of acute hepatitis in men and women, this indicator decreased by 1.11 times. At all stages of alcoholic liver disease, the average area of the nuclei was lower than the control value in men and women by 1.06 times only at the stage of acute hepatitis. In men and women, the NCR indicator was 1.07 times higher than the control level $(p=0.026)$ only at the AC stage.

Thus, as the analysis of domestic and foreign literature shows, studies carried out in this direction are few in number, the results obtained are ambiguous, and at the moment there is no unified system for the use of morphometric liver studies, techniques and analysis of its conduct $[15,16]$.

This determined the goal of the work - the need for further research and the choice of parameters of the vascular and parenchymal structural components of the liver, reflecting its morphofunctional state in acute and chronic alcohol intoxication, as well as in the control group (rapid death from traumatic brain injury at the scene) for their use in as additional diagnostic markers of these conditions.

\section{Materials and Methods}

110 deaths were investigated, including 20 cases of acute ethanol intoxication and 75 cases of chronic alcohol intoxication in persons with alcohol-induced liver pathology in the form of steatosis (AS) - 30, hepatitis (AH) - 20 and cirrhosis (AC) - 25. Acute intoxication ethanol corresponded to liver damage in the form of adaptive hepatopathy (AHP).

Alcohol levels ranged from 3.2 to $5.5 \mathrm{ppm}$ with acute ethanol intoxication, with chronic - in cases of steatosis - from 3.4 to $6.9 \mathrm{ppm}$, hepatitis - from 2.3 to $7.7 \mathrm{ppm}$, cirrhosis - from 0,4 to $2.5 \mathrm{ppm}$.

The control group consisted of 15 cases of rapid death of persons from traumatic brain injury at the scene of the incident; the deceased had no exogenous alcohol in their blood.

For histological examination, we used archival paraffin blocks, from which a series of $5 \mu \mathrm{m}$ thick sections were made and mounted on prepared slides.

For observation light microscopy and morphometric examination, histological preparations were stained with hematoxylin and eosin. Subsequently, photomicrographs of random fields of view of histological preparations were made with an OLYMPUS XC30 digital camera based on an OLYMPUS CX41 microscope (Japan) with a SWH $\times 10$ eyepiece magnification and UPLanFL $\times 10, \times 20, \times 40$ lenses (at least 10 visual fields in each histological section). Image Scope Color and cellSens 3 (Japan) computer programs for image analysis were used for morphometric data analysis. Statistical analysis with the calculation of the arithmetic mean and its error was performed using the statistical application Excel (Microsoft Office-2007) and the Statistica v. 6.

\section{Results and Discussion}

The morphometric study data are presented in Table 1.

It follows from it that in acute alcohol intoxication the analyzed parameters of the hemomicrocirculatory bed statistically insignificantly differ from the control group ( $\mathrm{P}$ (0.05). In chronic alcohol intoxication, there is a tendency $(\mathrm{P}<0.001)$ to change the diameters of the lumens of the central and interlobular veins, interlobular arteries and interlobular sinusoidal capillaries downward, especially in $\mathrm{AC}$ in comparison with the control and with other groups of $\mathrm{CAI}-\mathrm{AS}$ and AH.

At the same time, there is a statistically significant increase in the diameter of the interlobular bile ducts (P $<0.001$ ), the maximum values of which were recorded in hepatitis and liver cirrhosis.

To assess the level of morphofunctional activity of hepatocytes, we used the measurement of the area of hepatocytes and their nuclei. The area of the cytoplasm was calculated, which was equal to the difference between the areas of hepatocytes and their nuclei. To determine the NCR, the ratio of the area of the nucleus to the area of the cytoplasm was calculated. 
International Journal of Forensic Sciences

\begin{tabular}{|c|c|c|c|c|c|c|}
\hline \multirow[t]{2}{*}{ No. } & \multirow[t]{2}{*}{ Morphometric Indicator } & \multicolumn{5}{|c|}{ Indicator value $(\mathrm{M} \pm \mathrm{m})$} \\
\hline & & K & AGP & AS & $\mathrm{AG}$ & $\mathrm{AC}$ \\
\hline & \multicolumn{6}{|c|}{ Diameter, micron } \\
\hline 1. & central veins & $54,03 \pm 0,86$ & $55,1 \pm 0,6$ & $52,57 \pm 0,36$ & $47,03 \pm 1,36$ & $45,86 \pm 1,32$ \\
\hline 2. & interlobular veins & $87,80 \pm 1,84$ & $88,2 \pm 1,48$ & $84,74 \pm 1,36$ & $82,54 \pm 0,82$ & $80,51 \pm 1,14$ \\
\hline 3. & interlobular arteries & $25,62 \pm 2,41$ & $24,83 \pm 1,5$ & $22,57 \pm 1,43$ & $21,67 \pm 1,18$ & $20,09 \pm 1,27$ \\
\hline 4. & interlobular bilious ducts & $13,86 \pm 0,80$ & $14,34 \pm 0,5$ & $15,07 \pm 0,17$ & $17,59 \pm 1,36$ & $21,48 \pm 0,38$ \\
\hline \multirow[t]{2}{*}{5.} & $\begin{array}{c}\text { interlobular sinusoidal } \\
\text { capillaries }\end{array}$ & $28,36 \pm 0,93$ & $28,86 \pm 1,5$ & $26,8 \pm 1,02$ & $23,41 \pm 1,24$ & $21,95 \pm 1,16$ \\
\hline & \multicolumn{6}{|c|}{ Area, $\mu \mathbf{m}^{2}$} \\
\hline 1. & hepatocytes & $486,14 \pm 11,15$ & $481,76 \pm 10,25$ & $473,14 \pm 11,05$ & $450,89 \pm 5,77$ & $495,53 \pm 7,62$ \\
\hline 2. & nuclei & $58,89 \pm 1,86$ & $58,67 \pm 1,14$ & $58,06 \pm 1,86$ & $56,24 \pm 2,05$ & $62,94 \pm 1,63$ \\
\hline 3. & cytoplasm & $427,25 \pm 9,19$ & $423,09 \pm 9,11$ & $415,08 \pm 9,19$ & $394,65 \pm 3,72$ & $433,39 \pm 5,99$ \\
\hline 4. & $\begin{array}{c}\text { nuclear-cytoplasmic ratio } \\
\text { (NCR) }\end{array}$ & 0,137 & 0,138 & 0,139 & 0,142 & 0,145 \\
\hline
\end{tabular}

Table 1: Morphometric indicators of the structural components of the liver.

In acute ethanol poisoning and in alcoholic steatosis, the average area of hepatocytes, nuclei and cytoplasm, as well as the NCR, did not differ statistically significantly from the control group. In alcoholic hepatitis, there was a statistically significant decrease $(\mathrm{P}<0.05)$. The data obtained indicate significant changes in the nuclear apparatus in liver cirrhosis and indicate the activation of plastic processes in hepatocytes.>0.001) in the average area of hepatocytes, nuclei and cytoplasm relative to the control values and the steatosis group, while in alcoholic cirrhosis the average area of hepatocytes was higher than in the control and in other groups of chronic alcohol intoxication. In cirrhosis, high values of the average areas of nuclei and cytoplasm were also noted relative to other study groups. NCR indices had a statistically significant difference between the control groups and $\mathrm{AC}, \mathrm{AC}$ and $\mathrm{AC}$.

The results in the form of a decrease in the area of the vascular bed, cyto- and karyometric parameters obviously reflect the processes of an increase in dystrophic processes in hepatocytes and inflammatory-proliferative processes in the connective tissue, and indicate the tension of the capillaryconnective tissue structures, impaired blood circulation, bile and lymph outflow in the liver in chronic alcoholic intoxication, especially with hepatitis and cirrhosis.

\section{Conclusion}

Thus, the morphometric parameters of the liver identified by us in acute and chronic alcohol intoxication differ from each other, which allows us to recommend them as additional modern diagnostic criteria for acute and chronic alcohol intoxication.

These include:

- A decrease in the lumen of blood vessels in the hemomicrocirculatory bed;

- An increase in the diameter of the interlobular bile duct;

- An increase in the karyometric indicator - NCP.

The morphometric data obtained by us can be used as a comparison in the study of the pathomorphological features of the liver and in other pathological conditions.

\section{References}

1. Kovalev AV, Morozov YuE, Samokhodskaya OV, Bereznikov AV (2017) Alcohol-associated mortality in Russia (based on materials 2011-2016). Forensic medical examination 60(6): 4-8.

2. Morozov YuE, Porodenko VA, Travenko EN, Gornostaev DV (2019) Morphological markers of the functional activity of the liver in alcohol intoxication. Forensic medical examination 62(3): 37-41.

3. Droblenkov AV, Pankrashova EYu, Fedorov AV, Raptanova VA (2020) Plastic changes in neurons and oligodendrocytes in the cingulate cortex during ethanol poisoning and alcohol withdrawal in humans. Bulletin of Novgorod State University 1(117): 30-37.

4. Chrostek L (2014) Liver fibrosis markers in alcoholic liver disease. World J Gastroenterol 20(25): 8018-8023. 


\section{International Journal of Forensic Sciences}

5. Zakharash AD (2005) Computer morphometry in the diagnosis of chronic hepatitis. Ros zhurn gastroenterol hepatol coloproctol 15(1): 65.

6. Pigolkin YuI (2004) Morphological diagnostics of narcotic intoxication in forensic medicine - M. Medicine, pp: 304 .

7. Vavilov PS, Kataev SI, Chernenko NV, Novikova MM (2015) The Effect of ethanol on the vascular-parenchymal structures of the liver and hepatic regional lymph nodes. Journal of Anatomy and Histopathology 4(3): 30-31.

8. Zayko OA, Yakubenko OV, Astashov VV, Sindireva AV, Mozgovoy SI (2017) Morphofunctional transformations of the liver in conditions of acute intoxication with sodium selenite and their correction. Morphology 151(1): 33-36.

9. Bobrov IP, Lepilov AV, Guldaeva ZN, Dolgatov Ayu, Alymova EE, et al. (2019) Morphofunctional characteristics of the mast cell population of rat lungs with single and multiple deep immersion hypothermia. Modern problems of science and education. No. 2.

10. Stepanov YuM, Gaidar YuA, Didenko VI, Arzhanova Gyu (2015) Karyometric characteristics of hepatocytes at different stages of fibrosis and portal hypertension in patients with chronic diffuse liver diseases. Gastroenterology 4(58): s62-s67.

11. Blinkova NB (2017) Polyploidy of hepatocytes in liver regeneration in chronic hepatitis in patients from different age groups. NB Blinkova, SV Sazonov, SL Leontiev. - Yekaterinburg: Yunika pp: 106.

12. Antushevich AE, Grebenyuk AN, Khalyutin DA, Yartseva AA (2017) Effect of Glycyl-Cysteinyl-Glutamate Dinatium Inosine on Clinical Current and Outcome of Experimental Alcohol-Induced Liver Cirrosis. Toxicological Bulletin 5: 14-21.

13. Benyavsky MV (2005) Quantitative pathomorphology of hepatocytes in liver cirrhosis [Text]. MV Benyavsky, AA Dolzhikov. Bulletin of the Volgograd State Medical University: a quarterly scientific and practical journal 1 : 8-11.

14. EI Lebedeva (2016) Morphometric features of hepatocytes of white rats and humans with toxic liver damage. Achievements and innovations in modern morphology: collection of articles. tr. Scientificpractical. conf., From int. Participation, dedicated. 115th anniversary of the birth, Ministry of Health of the Republic. Belarus 2: S3-S6.

15. Zukov RA, Zhukov EL (2016) Predictive Significance of Karyocytometric Parameters in Renal Cell Cancer. Modern problems of science and education.

16. Chestnova Ayu (2016) The content and structure of glycogen in hepatocytes of normal and cirrhotic liver of rats and humans: author. Cand biol sciences SPb, pp: 25 . 